\title{
Measuring health-related quality of life of intellectually disabled children: a narrative review
}

\author{
Karthikayini Sasinthar $^{1 *}$, Abhijit V. Boratne ${ }^{1}$, Arun Sugumaran ${ }^{1}$, Raj Kumar Patil ${ }^{2}$
}

\begin{abstract}
${ }^{1}$ Department of Community Medicine, Mahatma Gandhi Medical College, Pondicherry, India
${ }^{2}$ Department of Community and Family Medicine, AIIMS, Bhopal, Madhya Pradesh, India
\end{abstract}

\author{
Received: 31 March 2021 \\ Accepted: 03 April 2021

\section{*Correspondence:} \\ Dr. Karthikayini Sasinthar, \\ E-mail: dr.karthikayini@gmail.com
}

Copyright: (C) the author(s), publisher and licensee Medip Academy. This is an open-access article distributed under the terms of the Creative Commons Attribution Non-Commercial License, which permits unrestricted non-commercial use, distribution, and reproduction in any medium, provided the original work is properly cited.

\begin{abstract}
To identify currently available measures of Health-related quality of life (HRQOL) for intellectually disabled children and to describe their content. A comprehensive retrieval of the English literature from 2001 to 2021 was done in the PubMed and Google Scholar. The terms 'Intellectual disability', 'Differently abled', 'Special children', 'Differently challenged', 'Mental retardation', 'Health-related quality of life', 'Quality of life', 'Burden of intellectual disability' and 'India' were used to identify measures of HRQOL for children's with intellectual disability. Several tools were identified to measure HRQOL for children with intellectual disability. Many have parent proxy as well as self-report form with good validity and reliability. Though, they were often developed with minimal involvement from families, focus on functioning rather than wellbeing, and have items that sometimes may cause emotional upset. When children with different health problems are compared, the degree of their particular health condition should be measured. Furthermore, overlap of items seems not to be a problem when the HRQOL of children with intellectually disability is studied. Hence, HRQOL assessments are useful for collecting information beyond the clinical symptoms of a health problem thus improving quality of care.
\end{abstract}

Keywords: Quality of life, Health-related quality of life, Intellectual disability, Children, Literature review, Questionnaires

\section{INTRODUCTION}

Health-related quality of life (HRQOL) is a multidimensional model that includes physical, mental, emotional, and social functioning domains associated with an illness or treatment. The Centres for Disease Control and Prevention (CDC) defines HRQOL as an individual's perceived physical and mental health over time. ${ }^{1}$ Health is fundamental to all human beings. WHO has defined health as "A state of complete physical, mental, and social wellbeing not merely the absence of disease or infirmity."2 HRQOL is a subjective measure of one's health status, mostly based on the individual, and also focuses more on the impact of a perceived health state on the ability to live a fulfilling life. ${ }^{3}$ From a health (or disease) perspective, the term 'quality of life' refers to patients' social, emotional, and physical well-being following treatment. ${ }^{4}$ HRQOL is a multidimensional concept which evaluates an individual's subjective perception about his/her effect of disease and treatment on physical, psychological, and social functioning domain. In medical practice, HRQOL instruments prioritize health problems as a support to take the clinical decision and to monitor responses to treatment. ${ }^{6,7}$ Hence this paper narrates the importance of measuring HRQOL of ID children with available literature in the scientific world.

\section{METHODS}

The necessary information regarding HRQOL and its importance among ID children were obtained through a review of literature in PubMed (including Medline) using 
terms 'Quality of life', 'Health related quality of life', 'Disabled children', 'Intellectually disability', 'Mental retardation', 'Special children', 'Differently abled', 'Differently challenged' and 'Global and India burden of disability' were obtained. The unpublished data on HRQOL were also collected included. The reference period was from the year 2000 to 2020 . Based on gathered references, the studies included in our paper was (1) studies that emphasis on ID children; (2) paper that was written in the English language; (3) paper that focuses on HRQOL measurements among ID children. The final preferred article was recently published in the scientific journal, the higher order of study designs (systematic reviews), and $\mathrm{s}$ multilateral agencies' publications. Analysis of the literature was synthesized into a narrative review report, highlighting our key findings by the following themes: Burden of ID, Importance of measuring HRQOL of ID children, tools to measure HRQOL.

\section{THE BURDEN OF INTELLECTUALLY DISABILITY}

WHO, claims that around $15 \%$ of population is living with a disability, and 110 million (2.2\%) people have very significant difficulties in functioning. It is found that one in twenty children less than 15 years of age live with a moderate to severe form of disability. ${ }^{8}$ According to the rights of persons with Disabilities Act 2016, there are seven categories of disability. One of the categories is ID, formerly known as mental retardation (MR). The ID is a condition categorised by significant limitations, in intellectual functioning such as reasoning, learning, problem-solving, and adaptive behaviour, which includes a range of everyday activities. The ID comprises two broad categories: specific learning disabilities (SLD) and autism spectrum disorder (ASD). ${ }^{7}$

National Sample Survey Organization (NSSO), a wing of the Ministry of Statistics and Programme Implementation, Government of India on their 76th round during July 2018 to December 2018, found the prevalence of disability in India to be $2.2 \%$, with $2.3 \%$ in the rural area and $2 \%$ in an urban area. ${ }^{9}$

\section{IMPORTANCE OF MEASURING HRQOL}

HRQOL is a multidimensional concept covering social, emotional, and physical functioning domain or wellbeing related to the patient's health condition. Measurement of HRQOL in individual with chronic health conditions can provide data on inpatient management and medical intervention to improve their health, resulting in increased survival rates and life expectancy. ${ }^{10}$ HRQOL can be measured by both self-report and proxy report tools. ${ }^{11}$

Mary Law et al in 2017 did a longitudinal study to measure the HRQOL among locomotor disabled individual using parent proxy form of child Health questionnaire (CHQ) among 427 individuals in Canada. ${ }^{12}$ They found significantly lower scores in the physical domain of health- related quality-of-life than the psychosocial domain for children with physical disabilities.

Surender et al did a cross-sectional study in India to assess HRQOL among 100 children three to ten years of age with Cerebral palsy (CP). They found significantly impaired HRQOL in CP children. The degree of disability is associated with physical independence, mobility, clinical burden, and social integration dimensions. ${ }^{13}$

Shilpee Chaudhary et al in 2019 conducted a communitybased cross-sectional study in the rural area of district Dehradun, India, to assess life quality among disabled persons. Two thousand six hundred people between 5-59 years of age were enrolled for the study. They concluded HRQOL domains had significant association with socio demographic characteristics. ${ }^{14}$

\section{TOOLS TO MEASURE HRQOL}

HRQOL is usually measured with 'instruments', which refers to patient questionnaires. HRQOL instruments are available as generic or disease-specific. ${ }^{15}$ The choice of HRQOL tool selection depends upon on researcher field of interest.

This HRQOL questionnaire is available as self-reporting forms and as parent reporting forms. In children, HRQOL includes the child's illness and family functioning impact. ${ }^{16}$ Self-reporting is the best standard of HRQOL measurements, but it is harder to get reliable information from children with a severe neurodevelopmental disorder. ${ }^{13}$

\section{Paediatric quality of life inventory 4.0 generic core scales $(\text { PedQL })^{17}$}

PedsQL was developed by James Varni widely used to measure HRQOL for children and adolescents from 2-to18 years of age. It consists of 23 items, namely Physical functioning ( 8 items), emotional functioning (5 items), social functioning (5 items), and school functioning (5 items) domain. PedsQL can be administered as a selfreport form and parent proxy form.

\section{Child health questionnaire $(\mathrm{CHQ})^{18}$}

The Child Health Questionnaire ${ }^{\mathrm{TM}}$ (CHQ) was developed in the US by Landgraf JM; Ware JE and widely used for measuring HRQOL for 5-18 years of age children. It consists of 11 domains with 87 items in Children form (CF87) and 98, 50, 28 items in CHQ- Parent form 50(CHQ-PF50), Parent form 28 (PF28) respectively.

\section{Child health and illness profile $(\text { CHIP })^{19}$}

The Child health and illness profile (CHIP) was developed in the US by Riley A; Starfield Band primarily used to access the health of children (Child Edition-CE) and adolescents (Adolescent edition-AE) ages 6 through 17 
years. CHIP-AE has 183 items across four domains, CHIP$\mathrm{CE} / \mathrm{CRF}$ has 45 items across five domains, and CHIPCE/PRF 76 items across five domains.

\section{WHO Quality of life instruments (WHOQOL-BREF $)^{20}$}

The WHOQOL-BREF instrument was developed by WHO, which consists of 26 items across four domains, namely physical (7 items), psychological (6 items), social relationship (3 items), and environment ( 8 items).

\section{KIDSSCREEN Quality of life inventory ${ }^{21}$}

KIDSCREEN 96, developed by Abel $\mathrm{T}$ et al assesses children's and adolescent subjective health and well-being. They were developed for all children from 8-18 years of age.

KIDSCREEN 52 version has 52 items across ten dimensions; KIDSCREEN 27 has 27 items across five dimensions, KIDSCREEN 10 with ten items.

\section{$K I N D L-R^{22}$}

The KINDL-R (Revidierter KINDer Lebensqualitatsfragebogen) 97 developed by U Ravens-Sieberer, M Bullinger for measuring HRQOL from 4-16 years of age, it consists of a self-report form and parent report form with 24 items across six domains for 8-16 years of age and 12 items across four dimensions for 4-7 years of age.

The Netherlands organization for applied scientific research academic medical centre child QOL questionnaire $^{23}$

The Netherlands organization for applied scientific research academic medical center (TNO/AZL) the Netherlands developed child QOL Questionnaire (TACQOL) for 8-15 years of age with 56 items across seven dimensions.

The youth quality of life instruments-research version $(Y Q O L-R)^{24}$

The youth quality of life instruments- research version (YQOL-R) developed by Patrick DL et al was used to measure HRQOL for 12-18 years. It consists of 41 perceptual items scale and a 16-item short-form available, the YQOL-SF, developed with Rasch methodology.

\section{Infant Toddler quality of life questionnaire (ITQOL) ${ }^{25}$}

Infant Toddler quality of life questionnaire (ITQOL) questionnaire was developed for two months to five years of age. It is a parent proxy form consisting of 43 items across twelve domains: physical functioning, growth, and development, bodily pain, general temperament /moods, general behaviour, getting along, general health, parentalemotional parental-time, family activities, family cohesion, change in health.

\section{Warwick child health morbidity profile $(\text { WCHMP })^{26}$}

Warwick child health morbidity profile was developed in the UK by Spencer measuring HRQOL of children between 0-5 years of age.

It is a parent proxy form with 16 items across eight domains: general health status, acute minor illness status, behavioural status, accident status, acute significant illness status, immunization status, chronic illness status, functional health status, and health-related quality of life.

\section{Behavioural, affective and somatic experience scale $(\mathrm{BASES})^{27}$}

The behavioural, affective, and somatic experience scale (BASES) a disease-specific tool for measuring HRQOL in bone marrow transplant children from less than one year to twenty years of age. It is available as a parent, nurse, and self-report form. It has 38 items across six domains, somatic distress, compliance, mood/behaviour, interactions, activity, and miscellaneous items.

\section{The paediatric oncology quality of life scale (POQOLS) ${ }^{28}$}

The paediatric oncology quality of life scale (POQOLS) was developed in the USA by Goodwin. It is diseasespecific tool for measuring HRQOL among cancer children less than eighteen years of age. It consists of 21 items across three domains, namely physical function and role restriction, emotional distress, and reaction to current medical treatment.

\section{Quality of life for children with otitis media $(O M-6)^{29}$}

Quality of life for children with otitis media (OM-6) is a disease-specific tool for otitis media children between six to twelve years of age. It has six items across six domains, namely items. Physical suffering, hearing loss, speech impairment, emotional distress, activity limitations, and caregiver concerns

\section{Haemophilia quality of life questionnaire (Haemo- $Q o L)^{30}$}

Haemophilia quality of life questionnaire (Haemo-QoL) was developed by a multinational group of experts that measures HRQOL among haemophilia patients with both parent and self-report form. It has short and long version with 21 to 77 and 8 items across ten domains: physical health, feeling, attitude, family, friends, other persons, sport and school, coping, treatment, and future.

\section{Cystic fibrosis questionnaire revised ${ }^{31}$}

Cystic fibrosis questionnaire revised form developed in Florida by Dr. Alexander Quittner for measuring HRQOL among cystic fibrosis patients from three to fifteen years of age. It consists of both self-report and parent proxy forms. It is a three items scale that includes nine quality of life 
domains, namely physical, role/school, vitality, emotion, social, body image, eating, treatment burden, and health perceptions.

\section{CONCLUSION}

The field of HRQOL is growing as evidenced by a variety of definitions and the number of upcoming measures. Selection of a HRQOL measure for clinical or research commitments is also dependent on one's purpose and one's definition of HRQOL and the domains of interest to be studied.

\section{ACKNOWLEDGEMENTS}

The researcher like to thank all faculty members of Department of Community Medicine of MGMCRI for constant support for our research work.

Funding: No funding sources Conflict of interest: None declared

Ethical approval: Not required

\section{REFERENCES}

1. Centre for Disease Control and prevention. Health Related Quality of Life (HRQOL), 2018. Available at: https://www.cdc.gov/hrqolconcept.htm. Accessed on 23 February 2021.

2. Kommu JVS, Jacob P. Specialty training in child and adolescent psychiatry in India. Eur Child Adolesc Psychiatry. 2020;29(1):89-93.

3. Hand C. Measuring health-related quality of life in adults with chronic conditions in primary care settings. Can Fam Physician. 2016;62(7):375-83.

4. Karimi M, Brazier J. Health, Health-Related Quality of Life, and Quality of Life: What is the Difference? Pharmacoeconomics. 2016;34(7):645-9.

5. Guyatt GH, Feeny DH, Patrick DL. Measuring health-related quality of life. Ann Intern Med. 1993;118(8):622-9.

6. Raj M, Sudhakar A, Roy R, Champaneri B, Joy TM, Kumar RK. Health-related quality of life in Indian children: A community-based cross-sectional survey. Indian J Med Res. 2017;145(4):521-9.

7. Government of India Ministry of Social Justice and Empowerment. The right of Persons with Disabilities Act, 2016 Gazette of India, 2016. Available at: http://disabilityaffairs.gov.in-content/page//act. Accessed on 23 February 2021.

8. WHO. Global disability action plan 2014-2021, 2021. Available at: http://www.who.int/disabilities. Accessed on 23 February 2021.

9. Ministry of Statistics and Program Implementation. Person with Disability in India, 2018. Available at: http://www.mospi.gov.insites/default/files/publicatio n_reportsReport_583_Final_0.pdf. Accessed on 23 February 2021.

10. Bray N, Noyes J, Harris N, Edwards RT. Measuring the health-related quality of life of children with impaired mobility: examining correlation and agreement between children and parent proxies. BMC Res Notes. 2017;10(1):377.

11. Law M, Hanna S, Anaby D, Kertoy M, King G, Xu L. Health-related quality of life of children with physical disabilities: a longitudinal study. BMC Pediatr. 2014;14(1):26.

12. Chaudhary S, Srivastava AK, Vyas S, Sharma N. Quality of Life among Disabled Persons- A CrossSectional Study in Rural Area of Dehradun District. Indian J Community Health. 2019;31(3):390-5.

13. Surender S, Nanjundagowda V, Sanjay K, Basavaraja G, Benakappa N, Benakappa A. Caregiver-reported health-related quality of life of children with cerebral palsy and their families and its association with gross motor function: A South Indian study. J Neurosci Rural Pract. 2016;7:223.

14. Chaudhary S, Srivastava AK, Vyas S, Sharma N. Quality of Life among Disabled Persons- A CrossSectional Study in Rural Area of Dehradun District. Indian J Community Health. 2019;31(3):390-5.

15. Dilipkumar JM. Health Related Quality of Life (HRQOL) Measures in Healthcare Delivery System: Indian Perspective. J Young Pharm. 2016;8(3):1647.

16. Dobhal M, Juneja M, Jain R, Sairam S, Thiagarajan D. Health-related quality of life in children with cerebral palsy and their families. Indian Pediatr. 2014;51(5):385-7.

17. Varni J. PedsQL TM (Pediatric Quality of Life Inventory TM), 2020. Available at: https://www.pedsql.org/pedsql3.html. Accessed on 23 February 2021.

18. Landgraf JM. Child Health Questionnaire (CHQ). In: Michalos AC, eds. Encyclopedia of Quality of Life and Well-Being Research. Switzerland: Springer, Dordrecht; 2014: 698-702.

19. Riley AW, Forrest CB, Starfield B, Rebok GW, Robertson JA, Green BF. The Parent Report Form of the CHIP-Child Edition: reliability and validity. Med Care. 2004;42(3):210-20.

20. Agnihotri K, Awasthi S, Chandra H, Singh U, Thakur S. Validation of WHO QOL-BREF instrument in Indian adolescents. Indian $\mathrm{J}$ Pediatr. 2010;77(4):381-6.

21. Sieberer U, Gosch A, Rajmil L, Erhart M, Bruil J, Duer W, et al. KIDSCREEN-52 quality-of-life measure for children and adolescents. Expert Rev Pharmacoecon Outcomes Res. 2005;5(3):353-64.

22. Bullinger M, Ravens SU. KINDL®- Revidierter KINDer Lebensqualitatsfragebogen, 2021. Available at: https://eprovide.mapitrust.org/instruments revidierterkinder-lebensqualitaetsfragebogen. Accessed on 23 February 2021.

23. Vogels T, Verrips GH, Verloove VSP, Fekkes M, Kamphuis RP, Koopman HM, et al. Measuring health-related quality of life in children: the development of the TACQOL parent form. Qual Life Res. 1998;7(5):457-65.

24. Salum GA, Patrick DL, Isolan LR, Manfro GG, Fleck MP. Youth Quality of Life Instrument-Research 
version (YQOL-R): psychometric properties in a community sample. J Pediatr. 2012;88(5):443-8.

25. Raat H, Landgraf JM, Oostenbrink R, Moll HA, Essink BML. Reliability and validity of the Infant and Toddler Quality of Life Questionnaire (ITQOL) in a general population and respiratory disease sample. Qual Life Res. 2007;16(3):445-60.

26. Spencer NJ, Coe C. The development and validation of a measure of parent-reported child health and morbidity: the Warwick Child Health and Morbidity Profile. Child Care Health Dev. 1996;22(6):367-79.

27. Phipps S, Hinds PS, Channell S, Bell GL. Measurement of behavioral, affective, and somatic responses to pediatric bone marrow transplantation: development of the BASES scale. J Pediatr Oncol Nurs. 1994;11(3):109-17.

28. Goodwin DA, Boggs SR, Graham PJ. Development and validation of the pediatric oncology quality of life scale. Psychological Assessment. 1994;6(4):321.
29. Rosenfeld RM, Goldsmith AJ, Tetlus L. Quality of life for children with otitis media. Archives of Otolaryngol Head Neck Surg. 1997;123(10):1049-54.

30. Bullinger M, Mackensen S. Haemo-QoL, 2014. Available at: https://haemoqol.questionnaiintroduction. Accessed on 23 February 2021.

31. Quittner A. Cystic Fibrosis Questionnaire (CFQ); Cystic Fibrosis Questionnaire Revised (CFQ-R), 2021. Available at: https://qol.thoracic.org/sections/ instruments/ae/pages/cfq-cfq-r.html. Accessed on 23 February 2021.

Cite this article as: Sasinthar K, Boratne AV, Sugumaran A, Patil RK. Measuring health-related quality of life of intellectually disabled children: a narrative review. Int J Community Med Public Health 2021;8:3652-6. 